\title{
Immunohistochemical Expression of "c-MET" in Breast Carcinomas
}

\author{
Nehal Ali Yehia Elleithy*, Gina Assaad Nakhla, Samar A. Elsheikh, Mona Salah Eldin Abdelmagid \\ Department of Pathology, Faculty of Medicine, Cairo University
}

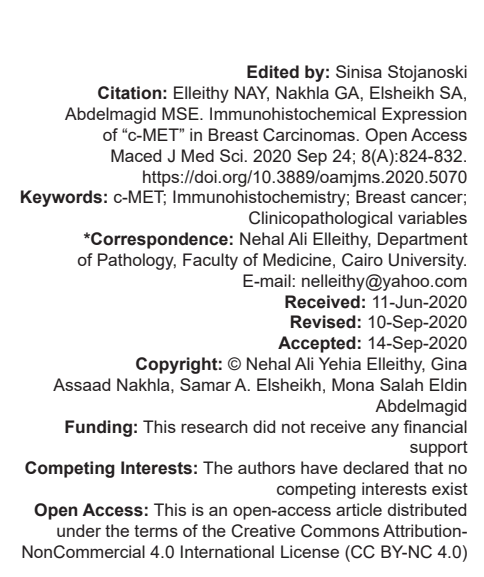

\section{Introduction}

Breast cancer is the second most common cancer in general and the most common female cancer accounting for a major cause of death among women [1].

Although great advances in targeted antihuman epidermal growth factor-2 (HER-2) receptor and hormonal therapies have ameliorated the general outcome for many types of breast cancer, various resistance mechanisms were later discovered [2].

Moreover, triple negative breast cancer (TNBC) is a subtype of breast cancer that essentially by definition lacks the expression of traditional therapeutic targets - namely, estrogen receptor (ER), progesterone receptor (PR), and HER-2 - and exhibits aggressive clinical course and the poorest survival of all breast cancers [3].

The above challenges called for investigating more therapeutic targets and the c-MET (mesenchymal epithelial transition) transmembrane surface growth factor receptor stood out as a potential target with a well-documented downstream signaling cascade triggering cell cycle progression, cell proliferation, motility, invasion, and survival culminating in an overall "invasive growth pattern" [4].

In the breast, c-MET is differentially overexpressed in carcinomatous cells as compared with benign tissues, making it a very attractive candidate for targeted therapy [5].

In addition, the c-MET receptor has a rich network of crosstalk with other growth factor receptors, especially the epidermal growth factor receptor family of receptors (including HER-2) and c-MET signaling was shown to contribute to resistance to many growth factor receptor-blocking therapies. Thus, c-MET antagonists may improve outcomes when used in combination with other growth factor inhibitors in targeted therapy strategies [6].

Regarding TNBCs, while some reports demonstrated a preferentially higher rate of c-MET expression in TNBCs [7], conflicting data were also presented [8]. Nevertheless, the most pronounced clinical benefit of c-MET blocking agents in breast cancers in early clinical trials was present in TNBC patients [9].

The main issue behind the failure of these trials has been related to patient selection, that is, the 
identification of effective pathological features and biomarkers to select those patients who are likely to derive most benefit from targeted c-MET inhibition allowing for the optimization of outcomes and minimizing unnecessary toxicity exposure [10].

In this study, we explored the expression of c-MET in immunohistochemical surrogates of molecular subtypes of breast cancer and its association with other clinicopathological variables that may predict its expression and possibly establish other rationales to refine patient selection for clinical trials.

\section{Materials and Methods}

\section{Retrieval of cases}

The material of this cross-sectional study was collected as 55 formalin-fixed paraffin embedded breast carcinoma tissue sections from archives of Pathology Department, Kasr AL-Ainy (Cairo University hospital) and private laboratories in the period between January 2015 and June 2017. The authors obtained the approval of the Ethical Committee in the Faculty of Medicine, Cairo University.

Inclusion criteria included cases of primary breast carcinomas that underwent a modified radical mastectomy or conservative breast surgery with or without axillary clearance. Exclusion criteria included cases with missing data (age of patients at presentation, tumor multifocality, tumor size (T), hormone receptor status, and HER-2 status), exhausted, poorly fixed or unavailable tissue blocks, and tru-cut biopsies.

\section{Histopathological examination}

Histopathological examination of $\mathrm{H}$ and $\mathrm{E}$ stained slides was performed for the confirmation of diagnosis of tumor histotype according to the 2012 WHO Classification of Tumors of the Breast [11].

Tumor histological grading for invasive duct carcinoma was confirmed according to the Nottingham Grading System [12]. The grading of other types was based mainly on the nuclear pleomorphism and mitotic activity [13]

The minimum criteria for perineural invasion diagnosis were the observation of cytologically malignant cells in the perineural space of nerves and in equivocal cases, the observation of total or near-total circumferential involvement was considered [14].

Lymphovascular invasion was defined as the presence of emboli of tumor cells within an endothelial lined space (lymphatic and/or blood vessel) outside the border of the tumor and/or presence of an artery or vein accompanying the involved vessel, and ensuring that the outline of the tumor cell aggregate does not exactly conform to the shape of the space in which it lies [15], [16].

Regarding the tumor infiltrating lymphocytes (TILs), they were scored following the recommendations of the International TILs Working Group 2014 [17]. We scored stromal TILs subjectively in 10\% increments and tumors were defined as High-TILs ( $\geq 30 \%)$ or LowTILs (<30\%) [18], [19].

\section{Staging and molecular subtyping basis}

Tumors staging was performed using the TNM staging system. The cases were further divided into anatomic stages and prognostic stage groups according to the latest edition of the American Joint Committee for Cancer (AJCC) staging manual [20].

ER, PR, HER-2, and Ki-67 status were retrieved from immunohistochemistry reports. ER, and PR-positive nuclear staining in $\geq 1 \%$ of tumor cells were considered positive according to the American Society of Clinical Oncology/College of American Pathologists guidelines recommendations [21]. HER-2 status was assessed according to Wolff et al., 2014 criteria [22]. Ki-67 status was retrieved for 29 cases only and a proliferation index $\geq 20$ was considered high [23].

Regarding the molecular subtyping, the tumors were classified according to the St. Gallen International Expert Consensus 2013 recommendations and St. Gallen International Expert Consensus 2017 recommendations [24], [25].

\section{evaluation}

\section{C-MET immunohistochemical staining and}

Immunohistochemical staining for c-MET (clone SP44, Ventana Medical Systems) was carried out using rabbit monoclonal antibody directed against c-MET membranous and/or cytoplasmic epitope. Fully automated staining was carried out on the BenchMark XT platform from Ventana utilizing the NIEW DAB detection kit using a section of non-small cell lung carcinoma as positive control (Figure 1).

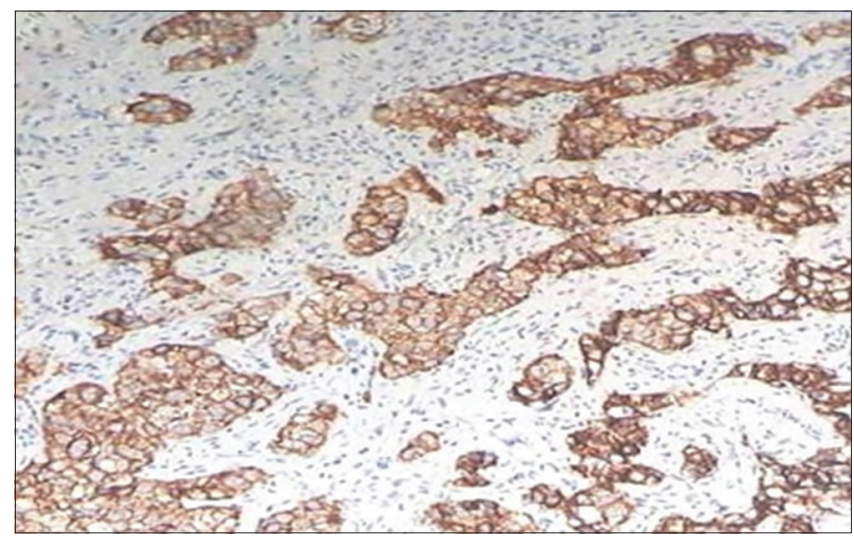

Figure 1: Non-small cell carcinoma of the lung positive control for $c-M E T$ expression ( $\times 200$ original magnification) 
Immunoreactivity for c-MET was observed as cytoplasmic and/or membrane staining in carcinoma cells using literature suggested criteria: A sample was considered c-MET positive if $>5 \%$ of definitive tumor cells showed immunohistochemical reactivity on the cell cytoplasm [26], [27].

\section{Statistical analysis}

We have investigated the association of c-MET expression with the age of patients at presentation, tumor multifocality, tumor size (T), lymph node status (N), AJCC anatomic and prognostic stage groups, histotype, histological grade, TILs, lymphovascular and perineural invasion, hormone receptor status, HER-2 status, Ki-67 expression, and immunohistochemical surrogates of molecular subtypes. Data were coded and entered using the statistical package SPSS (Statistical Package for the Social Sciences) version 25. Simple descriptive statistics (arithmetic mean and standard deviation) were used for quantitative data while frequency (count) and relative frequency (percentage) were used for categorical data. For comparing categorical data, Chisquare $\left(\chi^{2}\right)$ test was performed. Exact test was used instead when the expected frequency is $<5$. Logistic regression multivariate analysis was done to detect independent predictors of c-MET expression. $p<0.05$ is considered statistically significant and $p<0.01$ is considered statistically highly significant.

\section{Results}

This study included 55 cases of breast carcinoma. The age of them ranged from 22 to 86 years with a mean of $56.87 \pm 12.76$ years. Multifocal tumor masses were detected in $n=11,20 \%$. The majority of cases $74.55 \%$ were classified as T2, while T1 and T3 accounted for $12.73 \%$ of cases each. In about half of the selected cases $(51 \%)$, the detected lymph nodes were free of tumor deposits and $\mathrm{N} 1$ was the most common among node-positive tumors accounting for $25.4 \%$ of studied cases. The anatomic stage main group distribution was as follows: $9.1 \%$ of cases were Stage I, $63.64 \%$ were Stage II, and $20 \%$ were Stage III. Cases with unverified lymph node status were not classified. According to the AJCC prognostic staging classification, $30.91 \%$ of cases were Stage I, $40 \%$ of cases were Stage II, and $21.89 \%$ of cases were Stage III while $7.27 \%$ were unclassified. A total of 24 cases were reclassified according to this prognostic approach, with 14 downstaged cases (25.45\%) and ten upstaged cases (18.18\%).

The tumor histological subtypes were as follows; invasive duct carcinoma of no special type (NST) ( $n=42,76 \%$ ), and carcinoma with medullary features $(n=9,16 \%)$, lobular carcinoma including a single case of pleomorphic lobular carcinoma $(n=2,4 \%)$, and invasive papillary carcinoma and cribriform carcinoma $(n=1,2 \%)$ each (Figure 2).

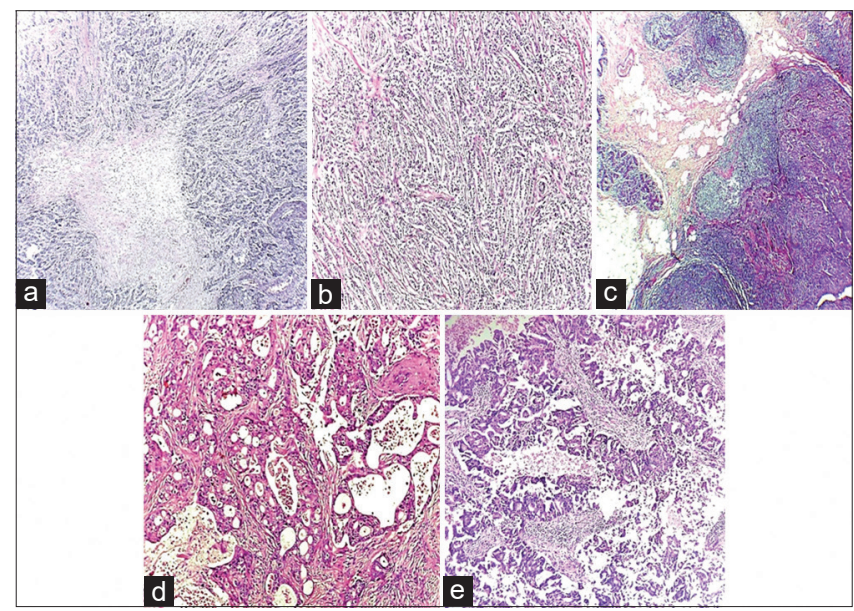

Figure 2: (a) Invasive duct carcinoma no special type, ( $H$ and $E \times 100$ original magnification). (b) Invasive lobular carcinoma ( $H$ and $E \times 100$ original magnification). (c) Carcinoma with medullary features ( $H$ and $E \times 40$ original magnification). (d) Cribriform carcinoma ( $H$ and $E \times 200$ original magnification). (e) Invasive papillary carcinoma no special type ( $H$ and $E \times 200$ original magnification)

Most of the studied cases were Grade II ( $n=43,78 \%)$ and the rest were Grade III $(n=12,22 \%)$. A high rate of TILs was observed in $(n=10,18 \%)$. Tumorassociated lymphovascular invasion was detected in $\mathrm{n}=15,27 \%$. Evidence of perineural invasion was detected in $n=5,9 \%$ (Figure 3 ).

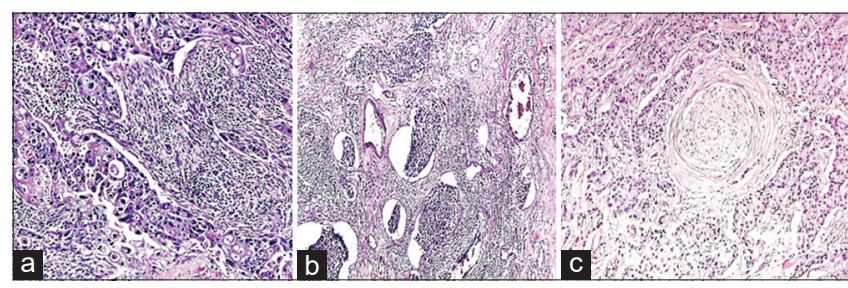

Figure 3: (a) Carcinoma with medullary features, high tumor infiltrating lymphocytes ( $H$ and $E \times 200$ original magnification). (b) Lymphovascular invasion ( $H$ and $E \times 100$ original magnification). (c) Perineural invasion ( $H$ and $E \times 400$ original magnification)

Positive ER expression was detected in $\mathrm{n}=24$, 43.64\%, positive PR expression in $n=20,36.36 \%$, and positive HER-2 in $\mathrm{n}=1,1.8 \%$. Ki-67 expression was retrieved for only 29 cases, 11 of which (37.93\%) showed high Ki-67 expression. The TNBCs accounted for $54.6 \%$ of studied cases and luminal $A$ was the most common subtype in the non-triple negative group accounting for $29 \%$, luminal B HER-2 negative represented $14.55 \%$ of cases, and a single HER-2 positive case was encountered accounting for $1.8 \%$.

The expression of c-MET was detected in 23 cases $(42 \%)$ (Figure 4$)$.

The TNBCs were associated with the highest rate of positive c-MET expression versus other molecular subtypes (luminal A and B HER2 negative), while the luminal $A$ subtype showed the highest rate of negative c-MET expression versus other molecular subtypes (luminal B HER-2 negative and triple negative) and these 


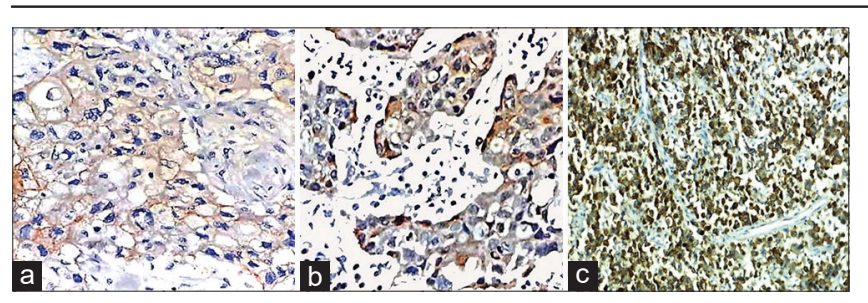

Figure 4: Positive c-MET expression with varying intensities (a) weak $c-M E T$ expression ( $\times 400$ original magnification), (b) moderate $c-M E T$ expression ( $\times 400$ original magnification), (c) strong c-MET expression ( $\times 100$ original magnification)

two relations were statistically significant $(p=0.003)$ and $(p=0.026)$, respectively. All tumors at extremes of age at presentation ( $<30$ and $>80$ years) were c-MET

Table 1: Relation of c-MET expression with clinicopathological variables

\begin{tabular}{|c|c|c|c|}
\hline Pathological characteristics & $\begin{array}{l}\text { C-MET } \\
\text { positive (\%) }\end{array}$ & $\begin{array}{l}\text { c-MET } \\
\text { negative (\%) }\end{array}$ & $\mathrm{p}$-value \\
\hline \multicolumn{4}{|l|}{ Age } \\
\hline Extremes ( $<30$ and $>80$ years $)$ & $4(100)$ & $0(0)$ & \multirow[t]{2}{*}{$0.026^{*}$} \\
\hline Other cases & $19(37.3)$ & $32(62.7)$ & \\
\hline \multicolumn{4}{|l|}{ Multifocality } \\
\hline Present & $2(18.2)$ & $9(81.8)$ & \multirow{2}{*}{0.097} \\
\hline Absent & $21(47.7)$ & $23(52.3)$ & \\
\hline \multicolumn{4}{|l|}{ T status } \\
\hline $\mathrm{T} 1$ & $2(28.6)$ & $5(71.4)$ & \multirow[t]{3}{*}{0.901} \\
\hline T2 & $18(43.9)$ & $23(56.1)$ & \\
\hline T3 & $3(42.9)$ & $4(57.1)$ & \\
\hline \multicolumn{4}{|l|}{ Node metastasis } \\
\hline Absent & $11(39.3)$ & $17(60.7)$ & \multirow[t]{2}{*}{0.54} \\
\hline Present & $11(47.8)$ & $12(52.2)$ & \\
\hline \multicolumn{4}{|l|}{$\mathrm{N}$ status } \\
\hline No & $11(39.3)$ & $17(60.7)$ & \multirow{4}{*}{0.522} \\
\hline N1 & $8(57.1)$ & $6(42.9)$ & \\
\hline N2 & $1(20)$ & $4(80)$ & \\
\hline N3 & $2(50)$ & $2(50)$ & \\
\hline \multicolumn{4}{|l|}{ Main anatomic stage groups } \\
\hline । & $1(20)$ & $4(80)$ & \multirow[t]{3}{*}{0.612} \\
\hline II & $16(45.7)$ & $19(54.3)$ & \\
\hline III & $5(45.5)$ & $6(54.5)$ & \\
\hline \multicolumn{4}{|l|}{ Main prognostic stage groups } \\
\hline I & $1(5.9)$ & $16(94.1)$ & \multirow[t]{3}{*}{$0.001^{*}$} \\
\hline II & $14(63.3)$ & $8(36.4)$ & \\
\hline III & $7(58.3)$ & $5(41.7)$ & \\
\hline Histotype & & & \\
\hline Carcinoma with medullary features & $7(77.8)$ & $2(22.2)$ & $0.026^{*}$ \\
\hline Other histotypes & $16(34.8)$ & $30(65.2)$ & \\
\hline Invasive duct, NST & $16(38.1)$ & $26(61.9)$ & 0.314 \\
\hline Other histotypes & $7(53.8)$ & $6(46.2)$ & \\
\hline Histological grade & & & \\
\hline I & $0(0)$ & $0(0)$ & $<0.001^{*}$ \\
\hline ॥ & $12(28.6)$ & $30(71.4)$ & \\
\hline III & $11(84.6)$ & $2(15.4)$ & \\
\hline TILs & & & \\
\hline High & $9(90)$ & $1(10)$ & $0.001^{*}$ \\
\hline Low & $14(31.1)$ & $31(68.9)$ & \\
\hline Perineural invasion & & & \\
\hline Present & $1(20)$ & $4(80)$ & 0.387 \\
\hline Absent & $22(44)$ & $28(56)$ & \\
\hline Lymphovascular invasion & & & \\
\hline Present & $6(40)$ & $9(60)$ & 0.867 \\
\hline Absent & $17(42.5)$ & $23(57.5)$ & \\
\hline ER & & & \\
\hline Positive & $4(16.7)$ & $20(83.3)$ & $0.001^{*}$ \\
\hline Negative & $19(61.3)$ & $12(38.7)$ & \\
\hline PR & & & \\
\hline Positive & $2(10)$ & $18(20)$ & $<0.001^{*}$ \\
\hline Negative & $21(60)$ & $14(40)$ & \\
\hline HER-2 & & & \\
\hline Positive & $1(100)$ & $0(0)$ & 0.418 \\
\hline Negative & $22(40.7)$ & $32(59.3)$ & \\
\hline Ki-67 & & & \\
\hline High & $4(36.4)$ & $7(63.6)$ & 0.717 \\
\hline Low & $8(44.4)$ & $10(55.6)$ & \\
\hline Luminal A & & & \\
\hline Present & $3(18.8)$ & $13(81.3)$ & $0.026^{*}$ \\
\hline Absent & $20(51.3)$ & $19(48.7)$ & \\
\hline Luminal B HER-2 negative & & & \\
\hline Present & $1(12.5)$ & $7(87.5)$ & 0.120 \\
\hline Absent & $22(46.8)$ & $25(53.2)$ & \\
\hline Triple negative & & & \\
\hline Present & $18(60)$ & $12(40)$ & $0.003^{*}$ \\
\hline Absent & $5(20)$ & $20(80)$ & \\
\hline
\end{tabular}

receptor, NST: No special type. positive and this relation was statistically significant $(p$ $=0.026$ ).

There was also a higher rate of statistically significant positive c-MET expression in tumors with advanced prognostic stage groups $(p=0.001)$ and despite that higher rates of positive c-MET expression were also found in advanced anatomic stage tumors, the later relation failed to demonstrate statistical significance $(p=0.612)$. A higher rate of positive c-MET expression was detected in carcinoma with medullary features versus other tumor histotypes and this difference was statistically significant $(p=0.026)$. A highly statistically significant association between positive c-MET expression and Grade III tumors $(p<0.001)$, high TILs $(p=0.001)$, ER negative status $(p=0.001)$, and PR negative status $(p<0.001)$ was also noticed.

There were no significant differences in c-MET expression regarding tumor multifocality $(p=0.097)$, T status $(p=0.901)$, lymph node status $N(p=0.522)$, perineural invasion $(p=0.387)$, lymphovascular emboli $(p=0.867)$, HER-2 status $(p=0.418)$, Ki $67(p=0.717)$, and luminal B HER-2 negative subtype $(p=0.120)$.

Details of the relation of $c-M E T$ expression with clinicopathological variables of studied cases are summarized in Table 1.

\section{Multivariate analysis}

Logistic regression was done to detect independent predictors of C-MET and exclude possible confounders, we found that the only independent predictors of c-MET expression were high TILs and PR negative status and all other variables were excluded by forward conditional regression (Table 2).

Table 2: Independent predictors of c-MET expression

\begin{tabular}{lccccccc}
\hline C-MET & B & S.E. & Df & p-value & OR & & $95 \% \mathrm{Cl}$ \\
\cline { 6 - 8 } & & & & & & Lower & Upper \\
\hline Lymphocytic infiltrate & 2.197 & 1.130 & 1 & $0.05^{*}$ & 9.000 & 0.982 & 82.496 \\
PR status & $-2.773-$ & 1.109 & 1 & $0.012^{*}$ & 0.063 & 0.007 & 0.549 \\
\hline B: Unstandardized coefficient, SE: Standard error, df: Degree of freedom, OR: Odds ratio, Cl: Confidence \\
interval, PR: Progesterone receptor.
\end{tabular}

\section{Discussion}

In this study, we investigated c-MET expression in various breast carcinoma immunohistochemical profiles and the association of c-MET expression with the other pathological variables. Expression of c-MET was detected in $42 \%$ of the cases in this study. Similar percent $(41.8 \%)$ was found using the same clone of monoclonal antibody (SP44, Ventana Systems) [28]. Lower rates as much as $3 \%$ and $12 \%$ were found by using the same clone with a higher positive cutoff value (>50\% tumor area) to assess marker "over" expression [8], [9]. A higher rate (about 69\%) was detected using a polyclonal antibody and a low cutoff value (5\% of tumor cells) to detect c-MET expression [27]. 
Of note, the wide range of c-MET positivity across different studies can be attributed to the different study populations as well as the significant variability in c-MET assessment and sampling techniques, usage of polyclonal versus monoclonal antibodies, different antibody clones, and variable scoring systems with variable cutoff values. The use of a monoclonal antibody, in our study, aimed to achieve better reproducibility. The choice of (SP44) clone against the intracellular domain of the receptor, stemmed from previous studies reporting that overexpression of this domain is far more common than the extracellular domain in breast cancer [29]. On a molecular level, results obtained with antibody SP44 were relatively consistent with quantitative real-time PCR and Western blot analysis data [28]. The use of full-face sections rather than tru-cut biopsies stemmed from the previous reports of heterogeneous c-MET expression [30]. The relatively low cutoff (5\% of tumor area) was according to previously suggested criteria and in view of the discordance between c-MET expression in tissue biopsy specimens using high immunohistochemical cutoff values and its expression in circulating tumor cells by flow cytometry in some studies [9], [26], [27].

The c-MET expression variation among different age groups (10-year intervals) was statistically significant, with the highest expression in extremes of age of our cohort ( $<30$ and above 80 years). Patients younger than 40 years were previously found to exhibit c-MET overexpression at higher proportions, though the difference was not significant $(p=0.099)$ [3]. These findings can be partially explained and are in line with the emerging evidence that young age breast carcinoma (YABC) is rather a biologically distinct entity with possibly specific molecular profiles that may include c-MET expression [31]. YABC is more likely to exhibit poor differentiation/high grade, advanced stages, and hormone receptor negativity, all of which may confound its association with c-MET [32]. Elderly patients generally have a higher genetic damage burden due to aging and thus may have a greater chance of incurring c-MET aberrations and may also have other confounding variables such as advanced stage or high grade which was truly the case in our study. In contrast, many studies found no significant correlation with patient age at presentation and c-MET expression. These studies either had a narrower patient age range that did not include our extreme age groups 37-69 years or did not stratify patients into age groups in relation to c-MET expression [33], [34]. Similarly, studies that broadly stratified patients into broad dual categories did not show a significant association of c-MET with age which might miss out on the subtle variation among the finer 10 years interval age groups in our study [8], [35], [36].

The percentage of c-MET positive cases was greater in unifocal tumors; however, the relationship between c-MET expression and tumor multifocality was statistically insignificant. To the best of our knowledge, the relationship between tumor multifocality and c-MET expression in breast cancers has not been thoroughly investigated and our results are in contrast to the association of tumor multifocality and c-MET expression observed in other organs [37], [38], [39], [40]. Thus, larger-scale studies investigating multifocality and c-MET genetic aberrations, protein expression, and associated biomarker expression in breast carcinoma might add or dismiss similar insights.

Higher rates of c-MET expression were detected in larger sized tumors (T2, T3), though the relationship between tumor size ( $T$ status) and $\mathrm{C}-\mathrm{MET}$ expression was statistically insignificant. Most studies similarly showed no significant association with c-MET expression [3], [8], [41]. However, a significant association between c-MET expression and largesized tumors was reported in a large sample size study ( $n=924)$ and in a meta-analysis reviewing many immunohistochemical and non-immunohistochemical technique based studies [28], [42]. These apparently divergent results were reported comparing c-MET scores (high vs. low expression) rather than the incidence of expression per se and the high c-MET scores associated with smaller tumor sizes lead to a postulation that $\mathrm{c}$-MET might have a more significant role in the early progression of smaller tumors [32]

The rate of positive c-MET expression was slightly higher in positive lymph node tumors, but the relationship between c-MET expression and lymph node status was statistically insignificant. A similar insignificant association was observed in the majority of encountered studies [3], [8], [27], [41]. However, a significant correlation with node involvement was found in a larger sized sample study using slightly higher cutoff value for c-MET expression [28]. On the contrary, Ho-Yen et al., 2014, by assessing scores rather than rates of expression found a significant relationship between high c-MET and node-negative tumors. The latter findings were explained by the high c-MET expressing basal-like tumors included in that study which have a tendency to metastasize more frequently through the hematogenous route and thus a higher incidence of node negativity [32].

The relationship between c-MET expression and anatomic stage (TNM) groups was statistically insignificant $(p=0.91)$. Similar findings were encountered [27], [42]. However, a significantassociation between c-MET expression and advanced stage was reported in studies having a large sample size or considering correlation with high score levels [28], [35]. In our study, highest rate of c-MET expression was detected in the most advanced prognostic Stage III; moreover, most of the prognostic Stage I tumors lacked c-MET expression and the relationship between c-MET expression and the prognostic stage groups was statistically highly significant. None of the compared studies assessing C-MET in breast cancer staged their cases according to the most recently published AJCC prognostic staging system. In our study, only the 
associations of c-MET expression with the prognostic stages, incorporating the more important grade and hormone status, were statistically significant. In light of this result, the prognostic stage might provide a more reasonable predictor for expression and a helpful tool in patient selection for further studies.

As regard the tumor histotype, no significant association with the invasive duct carcinoma, NST histotype, and similar results were found in the many encountered studies [3], [8], [27], [28]. However, the rate of positive c-MET expression was significantly higher among the carcinoma with medullary features ( $p=0.026)$. Yet, Ho-Yen et al., 2014, found that there is no correlation between c-MET scores and carcinoma with medullary features. This apparently divergent result might be due to their larger sample size and correlation with high c-MET scores [32]. Of note, most studies have not adequately addressed specifically the relationship between c-MET and the various histological subtypes, and comparison of c-MET expression was compared in invasive duct carcinoma NST versus minimally represented or an unspecified group of other histotypes [3], [8], [27], [28], [41].

The rate of c-MET positive expression was greater in the Grade III tumors versus Grade II tumors and this relation was statistically highly significant $(p<0.001)$. Similar results were approved in a metaanalysis [42]. Other studies showed no statistically significant relationship between tumor grade and c-MET. Wang et al., 2018, study had only six cases to represent low-grade tumors (Grades I and II) (6\% of total cases) which might have affected the statistical association with c-MET [8]. Constantinou et al., 2018, compared C-MET patients with well-differentiated tumors (Grade I) and moderately to poorly differentiated tumors (Grades II-III) [43]. Both Ren et al., 2016, and Constantinou et al., 2018, showed no significant association with tumor grade in exclusively sampled TNBC study population [3], [43]. The loss of a significant impact of the tumor grade status on c-MET expression in a certain group (triple negative cancers) in the later studies might indicate that the association with tumor grade is not in itself predictive of c-MET expression but rather it might be confounded by other variables (such as the receptor status) as will be further demonstrated by multivariate analysis in our study.

The rate of c-MET expression was significantly higher in tumors with high TILs. The relationship between c-MET expression and TILs in breast carcinomas has not been addressed in the previous studies; however, our results can be interpreted in view of the evidence in the literature for a role for c-MET signaling in promoting $T$ cell recruitment by inducing an autocrine chemokine loop [44]. This is further backed up by emerging data describing a TIL prosurvival effect of c-MET signaling by suppressing Programmed Death Ligand-1; an immunomodulatory molecule that triggers apoptosis of TILs, and dual inhibition of both molecules in experimental models synergistically enhances the tumor suppressing abilities [45].

The relationship between perineural invasion and c-MET expression was statistically insignificant; however, our results are in line with findings in other organ neoplasms as colorectal carcinoma and melanomas [46], [47]. This relation was not tackled in breast carcinoma, and in view of the few cases with perineural invasion in our study $(n=5)$, this relation merits further investigation.

The relationship between lymphovascular invasion and c-MET expression was statistically insignificant $(p=0.867)$. Similarly, there was no significant association between lymphovascular invasion with c-MET expression or its levels in many studies [8], [32], [43].

The rate of c-MET expression was significantly higher in ER-negative and PR-negative tumors and the relationship between hormone receptor status and C-MET expression was statistically highly significant $(p=0.001)$. Similar results were obtained in a large sample study [28]. However, other studies showed no significant association with the hormone receptor status by investigating a different c-MET antibody clone and patients receiving neoadjuvant therapy before c-MET assessment or by considering score levels of c-MET (high/low) expression [27], [35].

The relationship between $\mathrm{Ki}-67$ and $\mathrm{c}-\mathrm{MET}$ expression was statistically insignificant ( $p=0.717)$. A similar insignificant association was reported using Ki-67 cutoff value (14\%) close to ours (20\%) [3]. Significant association of c-MET with Ki-67 behavior using cutoff values for Ki-67 higher than our study $(>30 \%)$ was also described [43].

There was a significant variation among molecular subtypes in c-MET expression with significantly higher rate c-MET negativity in Luminal A subtype versus other subtypes and a higher rate of c-MET positivity among the triple negative subtype. Similar findings were found by Kim et al., 2014, and are in keeping with the Ho-Yen et al., 2015, review which showed a significant association of basal subgroup of triple negative tumors with c-MET expression [28], [41]. In contrast, Koh et al., 2014, found that c-MET positive tumors were less likely to have the triple negative subtype than c-MET negative ones. The latter study used a different antibody clone to asses c-MET, had a fewer number $(n=23)$ as well as a smaller proportion $(18 \%)$ of triple negative cases than our study and the patients were subjected to neoadjuvant therapy before c-MET evaluation which may alter its assessment [27].

The only independent predictors of c-MET were high TILs and negative PR status and all other variables were excluded by forward conditioned regression. Similarly, Carracedo et al., 2009, in a fluorescence in situ hybridization/immunohistochemical study showed that negativity for PR significantly correlated with c-MET expression in a multivariate analysis [48]. 


\section{Conclusion}

Tight clinicopathological correlation is needed in future clinical trials to identify clinically relevant score cutoff values for c-MET expression that can be translated into beneficial clinical responses. When considering patients for anti-c-MET clinical trials, patients at extremes of age ( $<30$ and above 80 years), and prognostic stage rather than the anatomic stage groups, Grade III tumors, carcinoma with medullary features, tumors with high TILs, and TNBCs are more likely to express c-MET and as such, they are suitable candidates. By excluding confounding factors, high TILs and PR negative status were especially important and independently significant in a multivariate analysis.

Tumor multifocality, tumor size, lymph node status, anatomic stage, lymphovascular or perineural invasion, and Ki-67 expression are less likely to reflect c-MET status. Many factors that failed to demonstrate a significant relation with c-MET, in our study, were either poorly represented (such as HER-2 positive tumors) or have been shown to significantly correlate with c-MET in other studies or in other organ cancers and as such merit further investigation in large scale studies.

To the best of our knowledge, tumors at extremes of age, carcinoma with medullary features, and prognostic stage were not previously recognized in the literature as significant predictors of c-MET expression. Moreover, high TILs relation with c-MET expression in breast carcinoma has never been addressed. The latter relation retains its weight in multivariate analysis and merits special consideration in the light of emerging back up data depicting a prosurvival effect of c-MET on TILs, as such, its utility may surpass patient selection to inspire a whole new paradigm in future studies and clinical trials.

\section{References}

1. Bray F, Ferlay J, Soerjomataram I, Siegel RL, Torre LA, Jemal A. Global cancer statistics 2018: GLOBOCAN estimates of incidence and mortality worldwide for 36 cancers in 185 countries. CA Cancer J Clin. 2018;68(6):394-424. https://doi. org/10.3322/caac.21492

PMid:30207593

2. Higgins MJ, Baselga J. Targeted therapies for breast cancer. J Clin Invest. 2011;121(10):3797-803. https://doi.org/10.1172/ jci57152

PMid:21965336

3. Ren X, Yuan L, Shen S, Wu H, Lu J, Liang Z. C-met and ER expression differences in basal-like and non-basal-like triplenegative breast cancer. Tumor Biol. 2016;37(8):11385-95. https://doi.org/10.1007/s13277-016-5010-5 PMid:26968553

4. Organ SL, Tsao MS. An overview of the c-MET signaling pathway. Ther Adv Med Oncol. 2011;3(1):S7-19. https://doi. org/10.1177/1758834011422556

PMid:22128289

5. Lindemann K, Resau J, Nährig J, Kort E, Leeser B, Annecke $\mathrm{K}$, et al. Differential expression of $\mathrm{C}-\mathrm{Met}$, its ligand HGF/SF and HER2/neu in DCIS and adjacent normal breast tissue. Histopathology. 2007;51(1):54-62. https://doi. org/10.1111/j.1365-2559.2007.02732.x

PMid: 17593080

6. Tang C, Cortez MA, Hong D, Welsh JW. Targeting the c-met kinase. In: Targeted Therapy in Translational Cancer Research. Hoboken, NJ, USA: John Wiley \& Sons, Inc.; 2015. p. 341-6. https://doi.org/10.1002/9781118468678.ch34

7. Yam C, Mani SA, Moulder SL. Targeting the molecular subtypes of triple negative breast cancer: Understanding the diversity to progress the field. Oncologist. 2017;22(9):1086-93. https://doi. org/10.1634/theoncologist.2017-0095

PMid:28559413

8. Wang M, Liang L, Lei X, Multani A, Meric-Bernstam F, Tripathy D, et al. Evaluation of C-MET aberration by immunohistochemistry and fluorescence in situ hybridization (FISH) in triple negative breast cancers. Ann Diagn Pathol. 2018;35:69-76. https://doi. org/10.1016/j.anndiagpath.2018.04.004

9. Rayson D, Lupichuk S, Potvin K, Dent S, Shenkier T, Dhesy-Thind $S$, et al. Canadian cancer trials group IND197: A phase II study of foretinib in patients with estrogen receptor progesterone receptor, and human epidermal growth factor receptor 2-negative recurrent or metastatic breast cancer. Breast Cancer Res Treat. 2016;157(1):109-16. https://doi. org/10.1007/s10549-016-3812-1

PMid:27116183

10. Puccini A, Marín-Ramos NI, Bergamo F, Schirripa M, Lonardi S, Lenz HJ, et al. Safety and tolerability of c-MET inhibitors in cancer. Drug Saf. 2019;42(2):211-33. https://doi.org/10.1007/ s40264-018-0780-x PMid:30649748

11. Lakhani SR, Ellis IO, Schnitt SJ, Tan PH, van de Vijver MJ. WHO Classification of Tumors of the Breast. $4^{\text {th }}$ ed. Lyon: IARC; 2012.

12. Elston CW, Ellis IO. Pathological prognostic factors in breast cancer. I. The value of histological grade in breast cancer: Experience from a large study with long-term follow-up. Histopathology. 1991;19(5):403-10. https://doi. org/10.1046/j.1365-2559.2002.14691.x PMid:1757079

13. Nakopoulou L, Gakiopoulou H, Keramopoulos A, Giannopoulou I, Athanassiadou P, Mavrommatis J, et al. C-met tyrosine kinase receptor expression is associated with abnormal beta-catenin expression and favourable prognostic factors in invasive breast carcinoma. Histopathology. 2000;36(4):313-25. https://doi. org/10.1046/j.1365-2559.2000.00847.x

PMid: 10759945

14. Dunn M, Morgan MB, Beer TW. Perineural invasion: Identification, significance, and a standardized definition. Dermatol Surg. 2009;35(2):214-21. https://doi. org/10.1111/j.1524-4725.2008.34412.x PMid:19215258

15. Hoda SA, Hoda RS, Merlin S, Shamonki J, Rivera M. Issues relating to lymphovascular invasion in breast carcinoma. Adv Anat Pathol. 2006;13(6):308-15. https://doi.org/10.1097/01. pap.0000213048.69564.26

16. Gujam FJ, Going JJ, Edwards J, Mohammed ZM, McMillan DC. The role of lymphatic and blood vessel invasion in predicting survival and methods of detection in patients with primary operable breast cancer. Crit Rev Oncol Hematol. 2014;89(2):231-41. https://doi.org/10.1016/j.critrevonc.2013.08.014 
PMid:24075309

17. Salgado R, Denkert C, Demaria S, Sirtaine N, Klauschen F, Pruneri $\mathrm{G}$, et al. The evaluation of tumor-infiltrating lymphocytes (TILs) in breast cancer: Recommendations by an international TILs working group 2014. Ann Oncol. 2015;26(2):259-71. https://doi.org/10.1093/annonc/mdu450

\section{PMid:25214542}

18. Polónia A, Pinto R, Cameselle-Teijeiro JF, Schmitt FC Paredes J. Prognostic value of stromal tumour infiltrating lymphocytes and programmed cell death-ligand 1 expression in breast cancer. J Clin Pathol. 2017;70(10):860-7. https://doi. org/10.1136/jclinpath-2016-203990

\section{PMid:28373294}

19. Tomioka N, Azuma M, Ikarashi M, Yamamoto $M$, Sato $M$, Watanabe $\mathrm{K}$, et al. The therapeutic candidate for immune checkpoint inhibitors elucidated by the status of tumorinfiltrating lymphocytes (TILs) and programmed death ligand 1 (PD-L1) expression in triple negative breast cancer (TNBC). Breast Cancer 2018;25(1):34-42. https://doi.org/10.1007/ s12282-017-0781-0 PMid:28488168

20. Hortobagyi GN, Connolly JL, D'Orsi CJ, Edge SB, Mittendorf EA Rugo HS, et al. Breast. In: Edge SB, Greene FL, Byrd DR, Brookland RK, Washington MK, Gershenwald JE, et al, editors. American Joint Committee on Cancer Cancer Staging Manual. $8^{\text {th }}$ ed. New York: Springer-Verlag; 2017. p. 570-610. https://doi. org/10.1007/978-3-319-40618-3_2

21. Hammond ME, Hayes DF, Dowsett M, Allred DC, Hagerty KL, Badve $\mathrm{S}$, et al. American society of clinical oncology/college of American pathologists guideline recommendations for immunohistochemical testing of estrogen and progesterone receptors in breast cancer (unabridged version). Arch Pathol Lab Med. 2010;134(7):e48-72. https://doi.org/10.1016/j. ypat.2010.11.008

PMid:20586616

22. Wolff AC, Hammond ME, Hicks DG, Dowsett M, McShane LM, Allison $\mathrm{KH}$, et al, American Society of Clinical Oncology; College of American Pathologists. recommendations for human epidermal growth factor receptor 2 testing in breast cancer: American society of clinical oncology/college of American pathologists clinical practice guideline update. Arch Pathol Lab Med. 2014;138(2):241-56. https://doi.org/10.5858/ arpa.2013-0953-sa PMid:24099077

23. Bustreo S, Osella-Abate S, Cassoni P, Donadio M, Airoldi M, Pedani F, et al. Optimal Ki67 cut-off for luminal breast cancer prognostic evaluation: A large case series study with a longterm follow-up. Breast Cancer Res Treat. 2016;157(2):363-71. https://doi.org/10.1007/s10549-016-3817-9

PMid:27155668

24. Goldhirsch A, Winer EP, Coates AS, Gelber RD, Piccart-Gebhart $\mathrm{M}$, Thürlimann $\mathrm{B}$, et al. Personalizing the treatment of women with early breast cancer: Highlights of the St Gallen international expert consensus on the primary therapy of early breast cancer 2013. Ann Oncol. 2013;24(9):2206-23. https://doi.org/10.1016/j.breast.2003.09.007 PMid:23917950

25. Curigliano G, Burstein HJ, Winer EP, Gnant M, Dubsky P, Loibl S, et al. De-escalating and escalating treatments for early-stage breast cancer: The St. Gallen international expert consensus conference on the primary therapy of early breast cancer 2017. Ann Oncol. 2017;28(8):1700-12. https://doi. org/10.1093/annonc/mdz235 PMid:28838210

26. Lee WY, Chen $\mathrm{HH}$, Chow NH, Su WC, Lin PW, Guo HR. Prognostic significance of co-expression of RON and MET receptors in node-negative breast cancer patients. Clin Cancer Res. 2005;11(6):2222-8. https://doi.org/10.1158/1078-0432. ccr-04-1761 PMid:15788670

27. Koh YW, Lee HJ, Ahn JH, Lee JW, Gong G. MET expression is associated with disease-specific survival in breast cancer patients in the neoadjuvant setting. Pathol Res Pract. 2014;210(8):494-500. https://doi.org/10.1016/j.prp.2014.04.002 PMid:24814255

28. Kim YJ, Choi JS, Seo J, Song JY, Lee SE, Kwon MJ, et al. MET is a potential target for use in combination therapy with EGFR inhibition in triple-negative/basal-like breast cancer. Int J Cancer. 2014;134(10):2424-36. https://doi.org/10.1002/ijc.28566 PMid:24615768

29. Kang JY, Dolled-Filhart M, Ocal IT, Singh B, Lin CY, Dickson RB, et al. Tissue microarray analysis of hepatocyte growth factor/ met pathway components reveals a role for met, matriptase, and hepatocyte growth factor activator inhibitor 1 in the progression of node-negative breast cancer. Cancer Res. 2003;63(5):11015. https://doi.org/10.1002/cncr.11335

PMid:12615728

30. Garcia S, Dales JP, Charafe-Jauffret E, Carpentier-Meunier S, Andrac-Meyer L, Jacquemier J, et al. Overexpression of c-met and of the transducers PI3K, FAK and JAK in breast carcinomas correlates with shorter survival and neoangiogenesis. Int $\mathrm{J}$ Oncol. 2007;31(1):49-58. https://doi.org/10.3892/ijo.31.1.49 PMid:17549404

31. Chollet-Hinton L, Anders CK, Tse CK, Bell MB, Yang YC Carey LA, et al. Breast cancer biologic and etiologic heterogeneity by young age and menopausal status in the Carolina breast cancer study: A case-control study. Breast Cancer Res. 2016;18(1):79. https://doi.org/10.1186/s13058-016-0736-y PMid:27492244

32. Ho-Yen CM, Green AR, Rakha EA, Brentnall AR, Ellis IO, Kermorgant S, et al. C-met in invasive breast cancer. Cancer. 2014;120(2):163-71. https://doi.org/10.1002/cncr.28386

33. Lengyel E, Prechtel D, Resau JH, Gauger K, Welk A Lindemann $\mathrm{K}$, et al. C-met overexpression in node-positive breast cancer identifies patients with poor clinical outcome independent of Her2/neu. Int J Cancer. 2005;113(4):678-82. https://doi.org/10.1002/ijc.20598 PMid:15455388

34. Zagouri F, Bago-Horvath Z, Rössler F, Brandstetter A, Bartsch R, Papadimitriou CA, et al. High MET expression is an adverse prognostic factor in patients with triple-negative breast cancer. $\mathrm{Br} J$ Cancer. 2013;108(5):1100-5. https://doi.org/10.1038/ bjc. 2013.31

PMid:23422757

35. Jia L, Yang X, Tian W, Gou S, Huang W, Zhao W. Increased expression of c-met is associated with chemotherapy-resistant breast cancer and poor clinical outcome. Med Sci Monit. 2018;24:8239. https://doi.org/10.12659/msm.913514 PMid:30444219

36. Kong DS, Song SY, Kim DH, Joo KM, Yoo JS, Koh JS, et al. Prognostic significance of c-met expressionin glioblastomas. Cancer. 2009;115(1):140-8. https://doi.org/10.1002/cncr.23972 PMid:18973197

37. Papotti M, Olivero M, Volante M, Negro F, Prat M, Comoglio PM, et al. Expression of hepatocyte growth factor (HGF) and its receptor (MET) in medullary carcinoma of the thyroid. Endocr Pathol. 2000;11(1):19-30. https://doi.org/10.1385/ep:11:1:19 PMid:12114654

38. Sweeney P, El-Naggar AK, Lin SH, Pisters LL. Biological significance of c-met over expression in papillary renal cell carcinoma. J Urol. 2002;168(1):51-5. https://doi.org/10.1016/ 
s0022-5347(05)64830-6

39. Wang SX, Lei L, Guo HH, Shrager J, Kunder CA, Neal JW. Synchronous primary lung adenocarcinomas harboring distinct MET Exon 14 splice site mutations. Lung Cancer. 2018;122:18791. https://doi.org/10.1016/j.lungcan.2018.06.019

40. Ho-Yen CM, Jones JL, Kermorgant S. The clinical and functional significance of c-Met in breast cancer: A review. Breast Cancer Res. 2015;17(1):52. https://doi.org/10.1186/s13058-015-0547-6 PMid:25887320

41. Zhao $X, Q u$ J, Hui $Y$, Zhang $H$, Sun $Y$, Liu $X$, et al. Clinicopathological and prognostic significance of c-met overexpression in breast cancer. Oncotarget. 2017;8(34):56758. https://doi.org/10.18632/oncotarget.18142

PMid:28915628

42. Constantinou C, Papadopoulos S, Karyda E, Alexopoulos A, Agnanti N, Batistatou A, et al. Expression and clinical significance of claudin-7, PDL-1, PTEN, c-Kit, c-Met, c-Myc, ALK, CK5/6, CK17, p53, EGFR, Ki67, p63 in triple-negative breast cancer-a single centre prospective observational study. In Vivo. 2018;32(2):303-11.35. https://doi.org/10.21873/ invivo. 11238

PMid:29475913

43. Komarowska I, Coe D, Wang G, Haas R, Mauro C, Kishore M, et al. Hepatocyte growth factor receptor c-met instructs $\mathrm{T}$ cell cardiotropism and promotes $\mathrm{T}$ cell migration to the heart via autocrine chemokine release. Immunity. 2015;42(6):1087-99. https://doi.org/10.1016/j.immuni.2015.05.014
PMid:26070483

44. Li H, Li CW, Li X, Ding Q, Guo L, Liu S, et al. MET inhibitors promote liver tumor evasion of the immune response by stabilizing PDL1. Gastroenterology. 2019;156(6):1849-61. https://doi.org/10.1053/j.gastro.2019.01.252

PMid:30711629

45. Gayyed MF, Abd El-Maqsoud NM, El-Hameed El-Heeny AA, Mohammed MF. c-MET expression in colorectal adenomas and primary carcinomas with its corresponding metastases. J Gastrointest Oncol. 2015;6(6):618-27.

PMid:26697193

46. Cruz J, Reis-Filho JS, Silva P, Lopes JM. Expression of c-met tyrosine kinase receptor is biologically and prognostically relevant for primary cutaneous malignant melanomas. Oncology. 2003;65(1):72-82. https://doi.org/10.1159/000071207 PMid:12837985

47. Carracedo A, Egervari K, Salido M, Rojo F, Corominas JM, Arumi $\mathrm{M}$, et al. FISH and immunohistochemical status of the hepatocyte growth factor receptor (c-Met) in 184 invasive breast tumors. Breast Cancer Res. 2009;11(2):R402. https://doi. org/10.1186/bcr2239

PMid: 19439036

48. Gajdos C, Tartter PI, Bleiweiss IJ, Bodian C, Brower ST. Stage 0 to stage III breast cancer in young women. J Am Coll Surgeons. 2000;190(5):523-9. https://doi.org/10.1016/ s1072-7515(00)00257-x

PMid:10801018 